Article

\title{
Copy Number Variation in SOX6 Contributes to Chicken Muscle Development
}

\author{
Shudai Lin ${ }^{1,+}{ }^{(1)}$, Xiran Lin ${ }^{1,+}$, Zihao Zhang ${ }^{1}$, Mingya Jiang ${ }^{1}$, Yousheng Rao ${ }^{2}$, Qinghua Nie ${ }^{1}$ \\ and Xiquan Zhang ${ }^{1, *}$ \\ 1 Guangdong Provincial Key Laboratory of Agro-Animal Genomics and Molecular Breeding, \\ Key Laboratory of Chicken Genetics, Breeding and Reproduction, Ministry of Agriculture, \\ College of Animal Science of South China Agricultural University, Guangzhou 510642, China; \\ shudailin@stu.scau.edu.cn (S.L.); daanxiran@163.com (X.L.); jayhozhang@163.com (Z.Z.); \\ jmyykl@stu.scau.edu.cn (M.J.); nqinghua@scau.edu.cn (Q.N.) \\ 2 Department of Biological Technology, Nanchang Normal University, Nanchang 330029, China; \\ rys8323571@aliyun.com \\ * Correspondence: xqzhang@scau.edu.cn; Tel.: +86-20-8528-5703 \\ + These authors contributed equally to this study.
}

Received: 31 October 2017; Accepted: 12 January 2018; Published: 17 January 2018

\begin{abstract}
Copy number variations (CNVs), which cover many functional genes, are associated with complex diseases, phenotypic diversity and traits that are economically important to raising chickens. The sex-determining region Y-box 6 (Sox6) plays a key role in fast-twitch muscle fiber differentiation of zebrafish and mice, but it is still unknown whether SOX6 plays a role in chicken skeletal muscle development. We identified two copy number polymorphisms (CNPs) which were significantly related to different traits on the genome level in chickens by AccuCopy ${ }^{\circledR}$ and $\mathrm{CNV}$ plex ${ }^{\circledR}$ analyses. Notably, five white recessive rock $(\mathrm{CN}=1, \mathrm{CN}=3)$ variant individuals and two Xinghua $(\mathrm{CN}=3)$ variant individuals contain a CNP13 (chromosome5: 10,500,294-10,675,531) which overlaps with SOX6. There is a disordered region in SOX6 proteins $265-579$ aa coded by a partial CNV overlapping region. A quantitative real-time polymerase chain reaction showed that the expression level of SOX6 mRNA was positively associated with CNV and highly expressed during the skeletal muscle cell differentiation in chickens. After the knockdown of the SOX6, the expression levels of IGFIR1, MYF6, SOX9, SHOX and CCND1 were significantly down-regulated. All of them directly linked to muscle development. These results suggest that the number of CNVs in the CNP13 is positively associated with the expression level of SOX6, which promotes the proliferation and differentiation of skeletal muscle cells by up-regulating the expression levels of the muscle-growth-related genes in chickens as in other animal species.
\end{abstract}

Keywords: chicken; copy number variation; $\mathrm{CNV}$; SOX6; growth; skeletal muscle; disorder region

\section{Introduction}

Copy number variations (CNVs) are defined as large DNA fragments with sizes ranging from 50 base pairs (bp) to 3 megabases $(\mathrm{Mb})$ deleted, inserted, duplicated, or translocated in the genome [1], and are a kind of important genomic structure variation. The same region adjacent to and partially overlapping multiple CNVs can be incorporated into a large genomic segment called the copy number variation region (CNVR). A CNVR with a frequency of at least $3 \%$ is defined as copy number polymorphism (CNP) [2]. The current research into complex diseases or phenotypic traits is mainly concentrated on association studies with single nucleotide polymorphisms (SNPs), relatively few association studies focus on CNV [3]. With the construction of the chicken genome CNV sketches of different breeds, the researchers also found many phenotypic traits associated with chicken CNVs. 
For example, the chicken's slow feathering is relative to the partial duplication between the PRLR and SPEF2 genes in the K loci of the chromosome (chr) Z [4]. The chicken's bean crown is caused by a large amplification fragment near the first intron of the sex-determining region Y-box 5 (SOX5) [5]. Visceral pigment deposition in Silkies is caused by the repetitive regions in the endothelin 3 (EDN3) gene [6]. A few CNVs are also associated with chickens' resistance or susceptibility to Marek's disease [7]. Therefore, the identification of CNV plays an important role in the research into some phenotypic traits and the process of disease susceptibility, and it is an important reference value for early breeding in chickens.

It has been reported that SOX6, one of the sex-determining region $\mathrm{Y}$ family members, plays essential roles in sex determination, embryonic and nervous system development and the formation of skeletal and various organs [8]. The transcription factors of the Sox family interact with each other and play a pivotal role in the target organ. For example, SOX5 and SOX6 factors directly or indirectly act on SOX9, and then regulate the proliferation and differentiation of chondrocytes $[9,10]$, cartilage formation and skeletal development [11]. Sox6 is a multi-faceted transcription factor involved in the terminal differentiation of many different cell types in vertebrates. It has been suggested that in mice as well as in zebrafish, Sox6 plays a pivotal role in the terminal differentiation of skeletal muscle as a key regulator of fast-twitch muscle fiber differentiation [12] or affecting the expression of sarcomere protein genes, as well as an indirect role through influencing the expression of transcription factors relevant to muscle development $[13,14]$.

Recently, according to the analysis of chicken CNV data [15], we found that the chicken SOX6 overlaps in the CNP13. We propose that this SOX6'S CNVR will directly or indirectly affect chicken growth and development through changing the expression level of SOX6. Thereby, in this study, we aim to study how the CNV influences the expression level of SOX6, and how SOX6 regulates chicken skeletal muscle development. Hence, we used association analysis between the CNP and economically important traits for raising chickens, and the targeted overexpression and interference of the SOX6.

\section{Materials and Methods}

\subsection{Ethical Approval}

The Animal Care Committee of South China Agricultural University (Guangzhou, China) approved this study (project code 2015-A003, approval on 18 May 2015). The animals involved in this study were humanely sacrificed as necessary to ameliorate suffering.

\subsection{Experimental Animals}

White recessive rock (WRR) is a fast-growing broiler line that was bred for meat, while Xinghua $(\mathrm{XH})$ is a Chinese native breed with slower growth, lower production, and more favorable meat quality. Three each of $\mathrm{XH}$ and WRR chickens at 7 weeks of age and three each of $\mathrm{XH}$ and WRR chickens at 27 weeks of age (12 total) were humanely euthanized and necropsied to collect tissue samples. First, scissors were used to cut open a cerebral longitudinal fissure and a cerebellar horizontal fissure, remove the brain meninges, and then the following samples were collected: brain (cerebral hemisphere), cerebellum, hypothalamus (in ventral thalamus) and pituitary (at the bottom of a brain; its anterior lobe and posterior interlobar separated by a connective tissue sheath). Secondly, the skin was cut carefully from the middle of the chest to the abdomen, and then the following samples were collected: sebum (subcutaneous chest fat), breast muscle (pectoralis major) and leg muscle (gastrocnemius). Thirdly, the viscus was explored using scissors to cut open the ribs and sternum, and then the following samples were collected: abdominal fat (fat around the gizzard), heart (pericardium, fat and arteriovenous removal), liver (right hepatic lobe), spleen (capsule removal), lung (spongy architecture and closed to the chest wall), kidney (garnet-red and located on both sides of the lumbosacral cavity), glandular stomach (end of esophagus, with many papillary protuberances on the surface of the inner wall), gizzard (elliptical and double convex mirror shape, content and corneum membrane of the inner wall 
removal), and ovary (connected to the oviduct, elliptical and mulberry). About $0.5 \mathrm{~g}$ of each tissue sample was collected and put in $2 \mathrm{~mL}$ frozen pipes, and quickly thrown into liquid nitrogen containers. All samples were stored at $-80{ }^{\circ} \mathrm{C}$ in a refrigerator for a long time. They were used to analyze the tissue expression patterns of candidate genes. The XH and WRR chickens were provided by the South China Agricultural University Poultry Breeding Farm (Guangzhou, China) and Guangdong Wen's Nanfang Poultry Breeding Co. Ltd. (Yunfu, China), respectively.

The genomic DNA was prepared from venous blood samples using a blood DNA extraction kit (Omega, Irving, TX, USA). Total RNA was extracted using Trizol reagent (Invitrogen, Carlsbad, CA, USA).

\subsection{CNV Population Genetics}

The SNPs were genotyped using a chicken $60 \mathrm{~K}$ SNP Illumina iSelect chicken array (Illumina, Towne Centre Drive San Diego, CA, USA) and collected according to previous published studies by Rao et al. [15] and Xie et al. [16] from 554 XH and WRR full-sib family chickens (33 F0 + 32 F1 + 489 F2 individuals) and were used to analyze each groups' CNP and the correlation between a candidate $\mathrm{CNP}$ and the economic traits.

The information on each CNVR for a family that contains family and individual CNV information can be represented in a specific genotype, such as $0 / 0(\mathrm{CN}=0$, homozygous deletion), $0 / 1(\mathrm{CN}=1$, single copy deletion), $1 / 1(\mathrm{CN}=2$, normal copy), $0 / 2(\mathrm{CN}=2$, multi-bit complex $\mathrm{CNV}), 1 / 2(\mathrm{CN}=3$, single copy increase) and $0 / 3(\mathrm{CN}=3$, multi-bit complex $\mathrm{CNV})$. The $\mathrm{CNV}$ inheritance in a family can be analyzed according to the CNV types of F0, F1 and F2 generations in the same CNVR of the same chromosome.

\subsection{Association Analysis}

The frequency of each CNVR group was calculated for each growth, carcass, and quality trait as follows: the growth traits recorded in the F2 generation included the weight at birth and at $7,14,21$, $28,35,42,49,56,63,77,84$ days of age; shank length at $42,49,56,63,77,84$ days of age; tibial diameter at $42,49,56,63,77,84$ days of age; and daily gain from $0-4$ weeks of age and $4-8$ weeks of age. The carcass traits are carcass weight, half eviscerated weight, eviscerated weight, brisket weight, leg weight, wing weight, head and neck weight, tibia claw weight, abdominal fat weight, abdominal fat belt width, subcutaneous fat thickness and fat septa width. The meat quality traits evaluated are muscle color, $\mathrm{pH}$ value, electrical conductivity, shear force, muscle fiber cross-sectional area, the department of hydraulic, intramuscular fat content, crude protein content. The generalized linear model (GLM) program of the SAS9.3 software (SAS Institute Inc., Cary, NC, USA) was used to analyze the association between each CNP and these three kinds of traits. The linear model used was as follows:

$$
\text { Yijkl }=\mu+\mathrm{Gi}+\mathrm{Sj}+\mathrm{Hk}+\mathrm{Fl}+\text { eijkl, }
$$

where $Y i j k l=$ corrected phenotypic value, $\mu=$ common mean, $G i=C N V$ genotypic effect, $S j=$ fixed gender effect, $H k=$ fixed hatch effect, $F l=$ random family effect, and eijkl = random residual. The false discovery rate (FDR) method was used for verifying significant CNPs. The $p$ values of a single CNP with each trait were sorted in ascending order, and the following formula was applied to obtain the FDR for each $\mathrm{CNP}=\mathrm{mP}(\mathrm{i}) / \mathrm{i}$, in which $m$ is the total number of traits, and $P$ is the $p$ value of the $i$ th trait [17].

\subsection{The Transformation of the Copy Number Polymorphism Regional Database}

The CNVRs from the WuGSC2.1 database version (May 2006 (WUGSC 2.1/galGal3)) [15] were positioned to the chicken genome of the Gallus_gallus-4.0 version using LiftOver tool software (http://genome.ucsc.edu/cgi-bin/hgLiftOver), comparatively analyzing with the National Center for Biotechnology Information (NCBI, https:/ / www.ncbi.nlm.nih.gov/) Basic Local Alignment Search 
Tool (BLAST, http:/ /blast.ncbi.nlm.nih.gov/Blast.cgi) to obtain the corresponding physical location of the CNP in the new database.

\subsection{Homology Analysis of Genes' Coding Sequences and Construction of Phylogenetic Tree}

The cDNA sequences of the SOX6 of the 12 species (Gallus gallus NP_001305380.1, Homo sapiens NP_001139291.1, Pan troglodytes XP_003312980.1, Canis lupus familiaris XP_005633754.1, Bos Taurus NP_001178347.1, Mus musculus NP_001264255.1, Rattus norvegicus NP_001019922.1, Xenopus tropicalis NP_001116887.1, Danio rerio NP_001116481, Ovis aries musimon XP_011992280.1, Coturnix japonica XP_015719574.1, Equus caballus XP_014597307.1) were obtained from the NCBI GeneBank. These sequences were download in FASTA format files and saved as txt format.

BLAST was used to analyze the homology of cDNA sequences among different species. SOX6 protein sequences of different species were mapped by using MEGA6.0 software [18] to construct a phylogenetic tree.

\subsection{Bioinformatics of SOX6}

Homologous construction of the tertiary structure of the SOX6 proteins was carried out by Swiss Model [19]. The SOX6 amino acid sequence was analyzed by GlobPlot online software [20] to predict the disordered region.

\subsection{Detection of DNA Copy Number Variations}

Both AccuCopy ${ }^{\circledR}$ (based on multiplex competitive amplification) [21] and CNVplex ${ }^{\circledR}$ (based on the multiplex ligation-dependent probe amplification) [22] assays developed by Genesky BioTech (Shanghai, China) were used to genotype six and four CNPs of 200 samples (100 XH chicken and 100 WRR chicken, male and female in half), respectively. The absolute copy number rounding principle was one (0.8-1.2), two (1.6-2.4), and three (2.6-3.4).

The copy number was calculated using the $2^{-\Delta \Delta \mathrm{Ct}}$ relative quantitative method, and the formula was as follows:

$$
\begin{array}{r}
\Delta \Delta \mathrm{Ct}=\Delta \mathrm{Ct} \text { (test) }-\Delta \mathrm{Ct} \text { (reference) }, \\
\mathrm{NR}=2-\Delta \Delta \mathrm{t}
\end{array}
$$

where test is the samples to be tested (samples that had a CNV within the region predicted by the microarray data); reference is the negative sample (with no copy number variation in the analyzing region); the $N R$ value of normal individuals was about one, of copy number gain individuals $\geq 1.5$, and of one copy loss individuals $\leq 0.5$ [23].

\subsection{Cell Culture}

In the study of muscle development, the skeletal muscle cell line, quail muscle clone 7 (QM7), is the ideal host for studying the expression of foreign genes, since it is a serum-inducible myogenic cell line. The cells replicate as myoblasts in medium containing serum. When switched to medium low concentration or without serum, the cells cease dividing and fuse to form large multinucleated myotubes. QM7 cells are useful for studying many aspects of muscle differentiation and gene expression. They also have the characteristics of easy cultivation, proliferation and differentiation, and a high transient transfection efficiency. Furthermore, the homology of the SOX6 gene in quails and chickens was 99\% (Supplementary File 1, Table S1).

Quail muscle clone 7 were cultured in 79.5\% M199 culture medium (Gibco, Grand Island, NY, USA) with 10\% fetal bovine serum (Hyclone, Logan, UT, USA), 10\% tryptose phosphate broth solution (Sigma-Aldrich, St. Louis, MO, USA) and 0.5\% penicillin/streptomycin (Invitrogen). Compared with the above, not everything changes, but $2 \%$ fetal bovine serum (Hyclone, Logan, UT, USA) induces QM7 cells to differentiate. Cells were cultured at $37^{\circ} \mathrm{C}$ in an incubator with $5 \% \mathrm{CO}_{2}$. 


\subsection{RNA Interference}

QM7 cells were transfected with $50 \mathrm{nM}$ of small interfering RNAs (siRNAs) targeting SOX6 (536-542 aa) using a Lipofectamine ${ }^{\circledR} 3000$ Transfection Kit (Invitrogen) according to the manufacturer's protocol. Total RNA was harvested $48 \mathrm{~h}$ later for quantitative real-time PCR (qRT-PCR) analysis. The siRNA sequences of negative control (si-NC) were: sense: 5'-UUCUCCGAACGUGUCACGUTT-3', antisense: 5'-ACGUGACACGUUCGGAGAATT-3'; and sense: 5'-GCAGAAGGAAGUAAAGCAATT-3', antisense: 5'-UUGCUUUACUUCCUUCUGCTT-3' for siRNA-SOX6 (GenePharma Co.; Ltd., Shanghai, China).

\subsection{Reverse Transcription and Quantitative Real-Time PCR}

The reverse transcription reaction was performed to analyze the expression levels of genes in the CNP area using the PrimeScript RT reagent kit (perfect real time) (Takara, Otsu, Japan) as described in the manufacturer's protocol. The qRT-PCR was conducted in the Bio-rad CFX96 Real-Time Detection system (Bio-rad, Hercules, CA, USA) using a KAPA SYBR FAST qPCR Kit (KAPA Biosystems, Wobrun, MA, USA). All primers are listed in Supplementary File 1, Table S2. The expression levels of the genes both in the CNP area or not were normalized with PCCA or $\beta$-actin.

\subsection{Cell Cycle Distribution Analysis}

In order to determine the effects of SOX6 on the cell cycle distribution, QM7 cells were cultured in 12-hole plate. When cell density reached 70\%, the overexpression vector (pcDNA3.1-SOX6), empty vector (pcDNA3.1), siRNA (si-SOX6) and si-NC were transiently transfected into the cells, with 4 repetitions in each group. All cells were sorted using flow cytometry at $48 \mathrm{~h}$ after transfection. Briefly, the cells were washed twice with ice-cold phosphate buffered saline (PBS) and fixed with $70 \%$ ice-cold ethanol overnight at $-20{ }^{\circ} \mathrm{C}$ until further processing. After incubation in $50 \mu \mathrm{g} / \mathrm{mL}$ propidium iodide (Sigma-Aldrich) containing $10 \mu \mathrm{g} / \mathrm{mL}$ RNase A (Takara, Otsu, Japan) and 0.2\% $(v / v)$ Triton X-100 (Sigma-Aldrich) at $4{ }^{\circ} \mathrm{C}$ for $30 \mathrm{~min}$, the cells were analyzed using a FACSAria II flow cytometer (BD Biosciences, San Jose, CA, USA) and ModFit Lt 4.1 software (Verity Software House, Topsham, ME, USA).

\subsection{Statistical Analysis}

Data were processed using the statistical software package SAS 9.1.3 (SAS Institute Inc.) and expressed as the mean \pm standard deviation (SD). A variance analysis was completed using a GLM procedure. $P<0.05$ was considered as a significant difference between the groups by $t$-test and one-way analysis of variance (ANOVA).

\section{Results}

\subsection{Population Genetics of Chicken Copy Number Variations}

From the analysis of nine chicken families, we found that there were 34 CNVRs belong to CNPs. Twenty CNVRs were consistent with Mendel's law of segregation in these three generations, and the remaining area CNVs in some individuals were not. Six CNVRs occurred in two chicken families (Supplementary File 1, Tables S3-S11. Fortunately, we uncovered 19 CNPs with a CNP frequency from $3.1 \%$ to $10 \%$, and 10 of them contained genes (Table 1 ).

Combining the genotype frequency of the candidate CNPs, which was detected by three kinds of method (Table 2), with the genetic regularity analysis, we found that some CNPs were unique in the family. For example, CNP2 and CNP4 were found only in the $\mathrm{XH} \times \mathrm{WRR}$ full sib resource F2 group. Repetitive events $(\mathrm{CN}=3)$ are basically inherited and can be inherited in a stable manner to the next generation, such as CNP10. 
Table 1. The frequency of copy number polymorphisms (CNPs) in Xinghua chicken $(\mathrm{XH}) \times$ white recessive rock chicken (WRR) full sib resource group.

\begin{tabular}{ccccccc}
\hline CNP & Chr. & Start & End & CN & Gene & Frequency (\%) \\
\hline CNP1 & 1 & 114669300 & 115092768 & 0,1 & EFHC2,MAOA & 3.83 \\
CNP2 & 2 & 24780291 & 24949275 & 1 & GLCCI1 & 5.66 \\
CNP3 & 4 & 88930573 & 89076844 & 3 & CD8A & 3.65 \\
CNP4 & 10 & 9320467 & 10038259 & 1 & ARPP19, KIAA1370,MYO5A & 3.65 \\
CNP5 & 16 & 220950 & 299166 & 0,3 & B-G, LOC396417,YFV & 9.49 \\
CNP6 & 18 & 3342968 & 3377149 & 1 & RAB40B,WDR45B & 4.01 \\
CNP7 & 20 & 105179 & 224625 & 1 & C20orf4 & 4.01 \\
CNP8 & 1 & 19027876 & 19083051 & 3 & NOT_FOUND & 3.83 \\
CNP9 & 1 & 66088686 & 66170851 & 1,0 & NOT_FOUND & 6.02 \\
CNP10 & 1 & 144183468 & 144308761 & 3 & NOT_FOUND & 8.76 \\
CNP11 & 1 & 167313565 & 167378938 & 1 & NOT_FOUND & 4.74 \\
CNP12 & 2 & 132873944 & 132955032 & 0,1 & NOT_FOUND & 6.57 \\
CNP13 & 5 & 12088601 & 12242199 & 1 & SOX6 & 6.75 \\
CNP14 & 8 & 9713469 & 9770642 & 1 & NOT_FOUND & 4.20 \\
CNP15 & 2 & 27005716 & 27140786 & 1 & NOT_FOUND & 3.28 \\
CNP16 & 2 & 137594135 & 137647003 & 1 & NOT_FOUND & 3.10 \\
CNP17 & 8 & 29199309 & 29221258 & 1 & NOT_FOUND & 3.10 \\
CNP18 & 13 & 716593 & 769986 & 3 & PCDHA & 3.19 \\
CNP19 & $Z$ & 12889235 & 12952470 & 0 & GHR & 3.19 \\
\hline
\end{tabular}

Chr., Chromosome; $\mathrm{CN}$, copy number.

Table 2. Detection of copy number variations (CNVs) in candidate CNPs.

\begin{tabular}{|c|c|c|c|c|c|c|c|c|c|}
\hline \multirow[b]{3}{*}{ CNP } & \multirow[b]{3}{*}{$\begin{array}{c}\mathrm{CN}^{2} \\
\text { (Genotype) }\end{array}$} & \multicolumn{8}{|c|}{ CNV Frequency (\%) } \\
\hline & & \multicolumn{4}{|c|}{ Illumine SNP Array } & \multicolumn{2}{|c|}{$\begin{array}{l}\text { AccuCopy }^{\circledR} \\
\text { CNVplex }^{\circledR}\end{array}$} & \multicolumn{2}{|c|}{$\begin{array}{l}\text { De-novo }{ }^{1} \\
\text { Sequencing }\end{array}$} \\
\hline & & $\mathbf{X H}$ & WRR & $\begin{array}{c}\mathrm{XH} \times \mathrm{WRR} \\
\mathrm{F} 1\end{array}$ & $\begin{array}{c}\mathrm{XH} \times \mathrm{WRR} \\
\mathrm{F} 2\end{array}$ & $\mathbf{X H}$ & WRR & $\mathbf{X H}$ & WRR \\
\hline CNP2 & $1(1 / 0)$ & -3 & - & - & 5.66 & - & - & - & - \\
\hline CNP4 & $1(1 / 0)$ & 7.14 & 14.29 & - & 3.40 & - & - & - & - \\
\hline CNP6 & $1(1 / 0)$ & - & 7.14 & 3.57 & 4.00 & - & - & - & 10.00 \\
\hline CNP10 & $3(1 / 2)$ & - & 14.29 & 17.86 & 8.20 & 6.00 & - & 100.00 & 100.00 \\
\hline \multirow[t]{2}{*}{$\mathrm{CNP} 13$} & $1(1 / 0)$ & 14.29 & 7.14 & - & 6.80 & - & 1.00 & - & - \\
\hline & $3(1 / 2)$ & - & - & - & - & 2.00 & 4.00 & 4.00 & 10.00 \\
\hline
\end{tabular}

${ }^{1}$ quality scores (Q-value) lower than 20 were removed from the raw RNA-Seq data using Perl scripts from Novogene Bioinformatics Technology Co., Ltd. (Beijing, China). At the same time, Q20, Q30, GC-content, and sequence duplication levels of the clean data were calculated. The clean data used in this study. ${ }^{2} \mathrm{CN}$, copy number. 3 "_" indicates none detected.

\subsection{Correlation between CNP and Chicken Economically Important Traits}

As shown in Table 3, three traits were strikingly associated with CNPs. The contribution rates of these CNPs to growth traits accounted for a range from $25 \%$ to $52 \%$. Among the 19 CNPs, CNP14 was significantly correlated with breast muscle conductivity and breast muscle dry matter content. Furthermore, CNP17 (deletion) showed a promotion effect on growth. However, there were no genes in these two regions (Table 1). Though CNP13 was not remarkably related to leg muscle fiber cross-sectional power $(p=0.0595)$, breast muscle fiber cross-sectional power $(p=0.074)$, leg muscle dry matter content $(p=0.085)$ or other economically important traits for raising chickens, it overlaps with the chicken SOX6 gene (Table 1). It was reported that Sox6 plays an important role in the fast-twitch muscle fiber differentiation of zebrafish and mice [12-14]. We want to know whether this gene acts on chicken muscle development or not. 
Table 3. Association of CNPs in the $\mathrm{XH} \times \mathrm{WRR}$ full sib F2 resource group and economic traits.

\begin{tabular}{cccccc}
\hline CNP ID & Trait & $p$ Value $^{\mathbf{1}}$ & Contribution Rate (\%) & \multicolumn{2}{c}{${\text { Mean } \pm \mathbf{S D}^{2}}^{\mathbf{2}}$} \\
\hline CNP14 & $\begin{array}{c}\text { breast muscle } \\
\text { conductivity }\end{array}$ & 0.04675 & 26.81 & $\begin{array}{c}8.19 \pm 0.67^{\mathrm{a}, 3} \\
(\mathrm{CN}=1)\end{array}$ & $\begin{array}{c}6.32 \pm 0.18^{\mathrm{b}} \\
(\mathrm{CN}=2)\end{array}$ \\
\hline $\begin{array}{c}\text { breast muscle dry } \\
\text { matter content (\%) }\end{array}$ & 0.0119 & 25.93 & $\begin{array}{c}25.23 \pm 0.34^{\mathrm{B}} \\
(\mathrm{CN}=1)\end{array}$ & $\begin{array}{c}26.19 \pm 0.21^{\mathrm{A}} \\
(\mathrm{CN}=2)\end{array}$ \\
\hline CNP17 & $\begin{array}{c}\text { 63 d tibia } \\
\text { length (mm) }\end{array}$ & 0.0029 & 52.50 & $\begin{array}{c}90.67 \pm 3.49 \mathrm{~A} \\
(\mathrm{CN}=1)\end{array}$ & $\begin{array}{c}76.1 \pm 0.69 \mathrm{~B} \\
(\mathrm{CN}=2)\end{array}$ \\
\hline
\end{tabular}

${ }^{1} p$ value corrected for false discovery rate (FDR), FDR $\leq 0.05$ was considered a significant difference. ${ }^{2}$ Standard Deviation (SD). ${ }^{3}$ In the same line, different capital letters indicate a remarkable significant difference $(p<0.01)$, different small letters indicate significant difference $(p<0.05)$.

\subsection{Candidate Genes in CNPs Related to Chicken Growth Traits}

Among the 12 CNPs associated with growth traits, the CNVRs of CNP2, CNP3, CNP4, CNP6 and CNP13 contain functional genes. Such CNPs will be considered a candidate CNP (Table 4). Thereby, there were six CNPs considered as functional candidate CNPs.

Table 4. The functions of the candidate CNPs.

\begin{tabular}{lccc}
\hline CNP ID & CN & Gene & Up or Down-Regulate Growth Traits \\
\hline CNP2 & 1 & GLCCI1 & $\uparrow$ \\
CNP3 & 3 & CD8A & $\downarrow$ \\
CNP4 & 1 & $A R P P 19$, KIAA1370,MYO5A & $\downarrow$ \\
CNP6 & 1 & WDR45B, RAB40B & $\uparrow$ \\
CNP10 & 3 & NOT FOUND & $\uparrow$ \\
CNP13 & 1 & SOX6 & $\downarrow$ \\
\hline \multicolumn{2}{l}{ CN, copy number. } & Arrows $\uparrow$ and $\downarrow$ represent that genes up-regulate or down-regulate chicken growth \\
traits, respectively. &
\end{tabular}

The qPCR validation results (Figure 1 and Table 5) initially proved the true existence of CNVs, and for more than $80 \%$ of the individuals' CNV type was proven. However, the qPCR results were not exact in the quantification of the absolute copy number of each individual. The CNV of each CNP formed haplotype blocks with neighboring SNPs. However, we did not find a strong linkage between CNV and SNP from the linkage disequilibrium (LD) analysis, which means that we did not find out the tag-SNP of the CNPs (Supplementary Figure S2).

Table 5. qRT-PCR results verifying six CNPs.

\begin{tabular}{ccccc}
\hline CNP ID & CNP Region & Type & Validation & Positive Verification Rate (\%) \\
\hline CNP2 & chr2: $24780291-24949275$ & LOSS & Yes & 80 \\
CNP3 & chr4: $88930573-89076844$ & GAIN & Yes & 100 \\
CNP4 & chr10: $9320467-10038259$ & LOSS & Yes & 80 \\
CNP6 & chr18: $3342968-3377149$ & LOSS & Yes & 80 \\
CNP10 & chr1: $144183468-144308761$ & GAIN & Yes & 100 \\
CNP13 & chr5: $12088601-12242199$ & LOSS & Yes & 100 \\
\hline
\end{tabular}




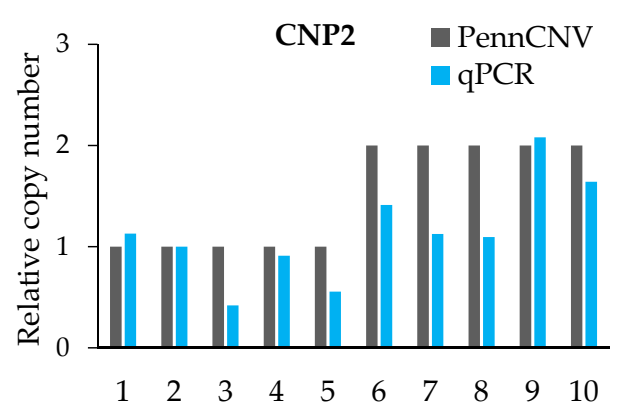

(a)

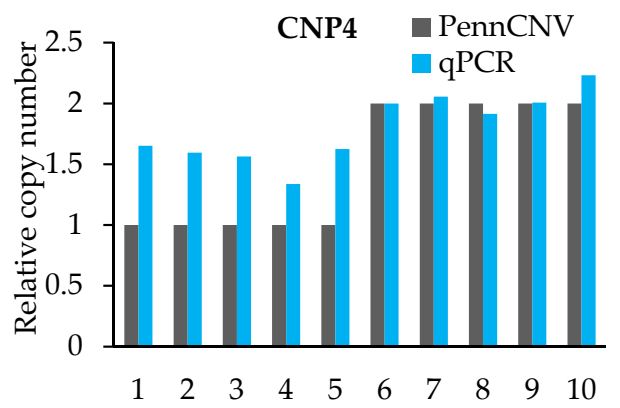

(c)

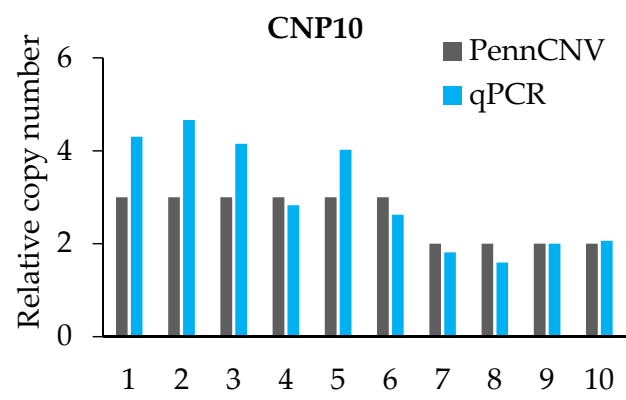

(e)

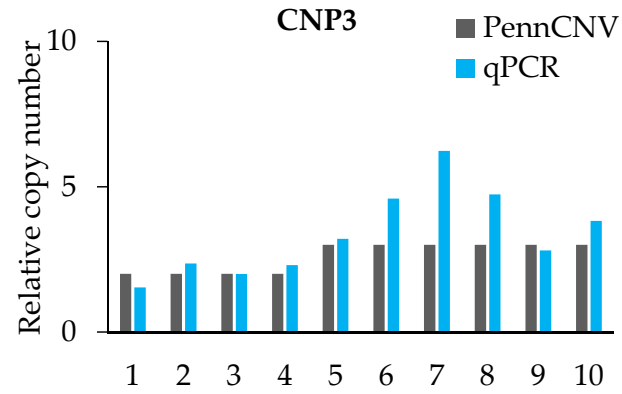

(b)

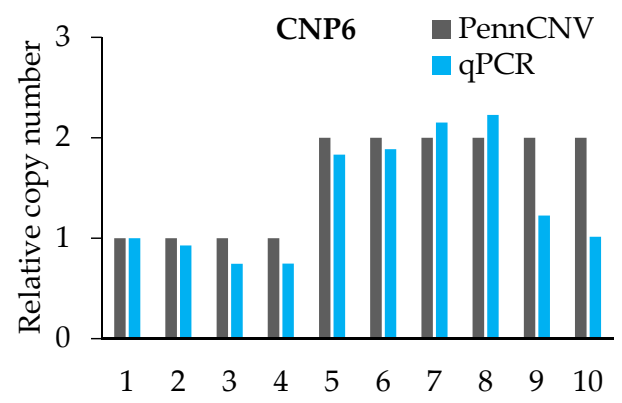

(d)

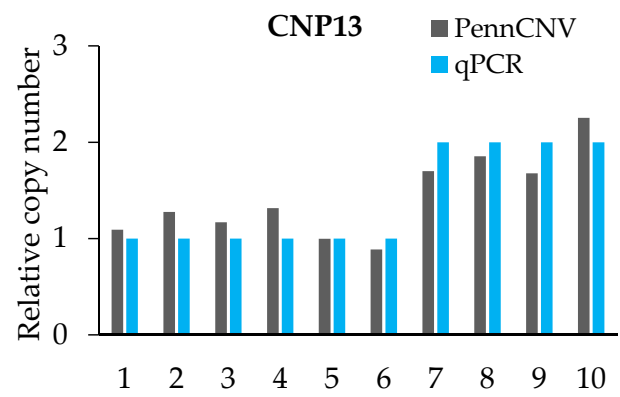

(f)

Figure 1. Quantitative real-time PCR (qRT-PCR) verified six CNPs. (a-f) The expression levels of CNPs are related to that of the control gene PCCA. PennCNV is a hidden Markov model (HMM)-based approach, for the kilobase-resolution detection of CNVs from Illumina high-density single nucleotide polymorphisms (SNP) genotyping data [15].

\subsection{The CNV in CNPS}

From the AccuCopy ${ }^{\circledR}$ assay result (Table 6), both CNP3 and CNP10 have a high sequence homology that is unable to gain the rounding number. There are no CNVs in glucocorticoid-induced transcript 1 (GLCCI1) (CNP2), cAMP-regulated phosphoprotein (ARPP19) (CNP4), and RAB40B, members of the RAS oncogene family $(R A B 40 B)$, a family with sequence similarity among 214 member A (FAM214A) (CNP6). However, heterozygous deletion in SOX6 (CNP13) was found in WRR chickens. From the CNVplex ${ }^{\circledR}$ assay results, among $100 \mathrm{WRR}$ and $100 \mathrm{XH}$ chickens, there were no individuals with CNVs in the myosin VA (MYO5A) (CNP4) and WD repeat domain 45B (WDR45B) (CNP6), while there were two XH and two WRR chickens with $\mathrm{CN}=3$ of SOX6 (CNP13) (Figure 2, Supplementary File 2), five WRR hens with $\mathrm{CN}=1$ or $\mathrm{CN}=3$, and five $\mathrm{XH}$ individuals with $\mathrm{CN}=3$ in $\mathrm{CNP} 10$ (Supplementary File 1, Figure S3). Thus, we focused on SOX6 (CNP13) in the next study. 
Table 6. The result of the AccuCopy ${ }^{\circledR}$ assay.

\begin{tabular}{ccccc}
\hline \multirow{2}{*}{ CNP } & \multirow{2}{*}{ Region $^{1}$} & \multicolumn{3}{c}{ CNV Type } \\
\cline { 3 - 5 } & & $\mathbf{X H}$ & \multicolumn{2}{c}{ WRR } \\
\hline CNP2 & GLCCI1E04 & $\mathrm{CN}=2$ & $\mathrm{CN}=2$ \\
\hline CNP4 & ARPP19E02 & $\mathrm{CN}=2$ & $\mathrm{CN}=2$ \\
\hline \multirow{2}{*}{ CNP6 } & RAB40BE03 & $\mathrm{CN}=2$ & $\mathrm{CN}=2$ & \\
\cline { 2 - 5 } & FAM214AE05 & $\mathrm{CN}=2$ & $\mathrm{CN}=2$ & \\
\hline CNP13 & SOX6E09 & $\mathrm{CN}=2$ & $\mathrm{CN}=2$ & $\mathrm{CN}=1(1 \%)^{1}$ \\
\hline
\end{tabular}

${ }^{1}$ The frequency in the experimental population.

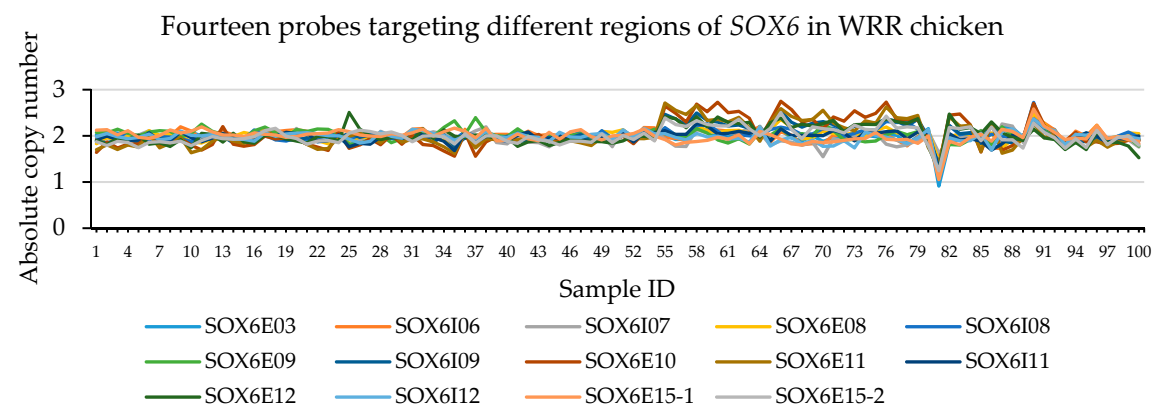

(a)

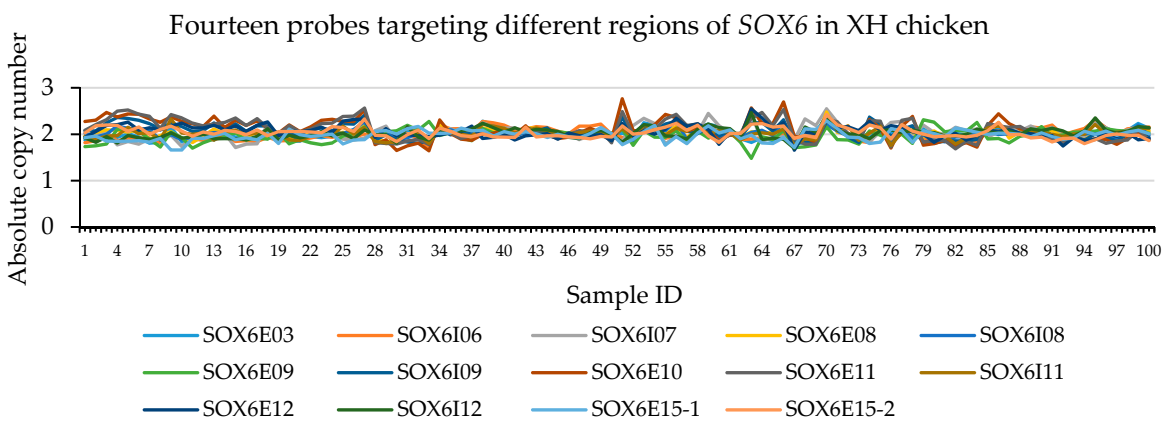

(b)

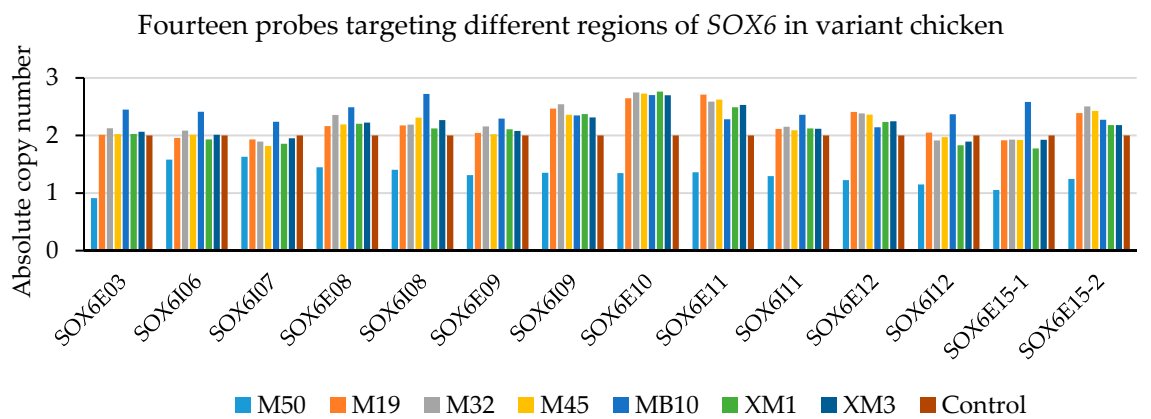

(c)

Figure 2. The $\mathrm{CNV}{ }^{\circledR}$ assay result for SOX6 (CNP13). The different colors represent the individual' absolute copy number of SOX6 in the different positions in the CNP13. There are two XH individuals with absolute copy values in exons 10 and 11 of $S O X 6$ of about $2.6(\mathrm{CN}=3)$ (sample ID 51 and 66 shown in (a), which consist with XM1, XM3 in (c)); others were normal individuals $(\mathrm{CN}=2)$. In WRR chickens, there is a single individual with absolute copy number less than $1.2(\mathrm{CN}=1)$ (sample ID 81 shown in (b), which consists with M50 in (c)), and four individuals with an absolute copy values in exons 10 and 11 of SOX6 greater than $2.5(\mathrm{CN}=3)$ (sample ID 55, 66, 76 and 90 shown in (b), which consist with M19, M32, M45 and MB10 in (c), respectively). 


\subsection{The CNVs in CNP Structural Mapping}

Chicken SOX6 is located in chromosome 5 (chr5), with a total length of 179,522 bp, including 15 exons, 14 introns, and the full-length of its coding sequence is $2370 \mathrm{bp}$. Chicken SOX6 (Ensemble, Galgal4: CM000097.3) overlaps with the CNP13 (Figure 3). The gene's CNV occurs in some individuals in both the XH and WRR chicken lines, and SOX6 may play an important role in the chicken's growth traits.

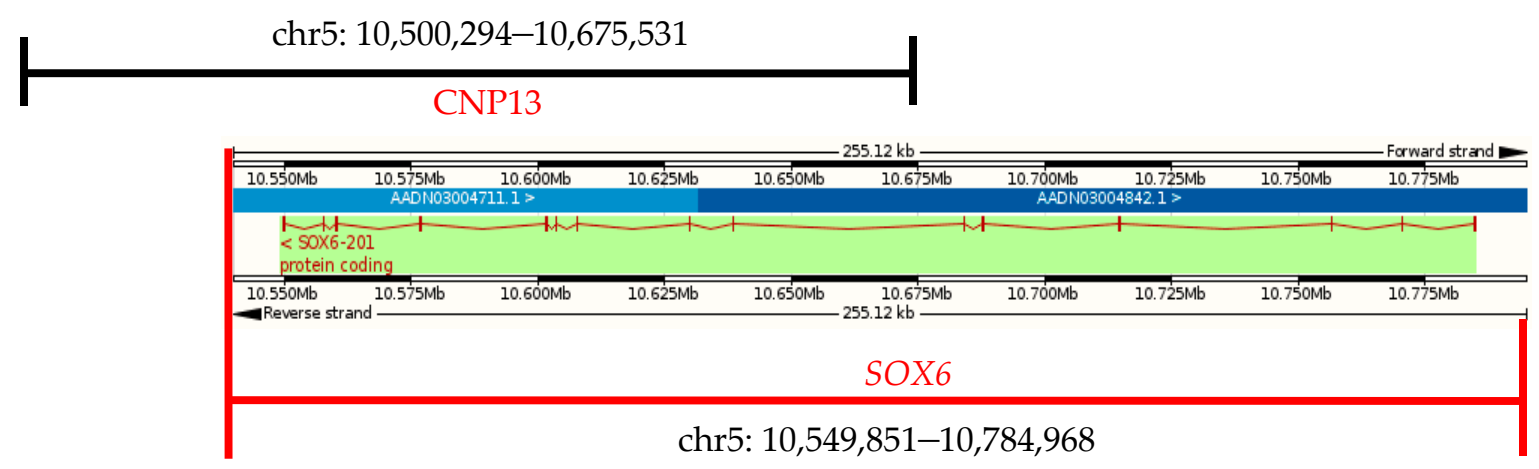

Figure 3. Gene location of chicken SOX6.

\subsection{The Expression Level of SOX6 is Positively Related to Its Copy Number}

In seven-week-old $\mathrm{XH}$ chickens, SOX6 is expressed in different tissues, such as cerebellum, cerebrum, hypothalamus, pituitary, heart, liver, spleen, lung, kidney, glandular stomach, gizzard, breast muscle, leg muscle, sebum, abdominal fat, and ovary (Figure 4). The highest expression was in the breast muscle and pituitary gland, secondly in the cerebellum, kidney, leg muscle and heart, with lower expression levels in other tissues. Similar to the trend of SOX6 mRNA in different tissues of seven-week-old XH chickens, SOX6 is expressed highly in the breast muscle, leg muscle, pituitary, heart, cerebellum, and kidney of both 27-week-old XH and WRR chickens (Figure 5).

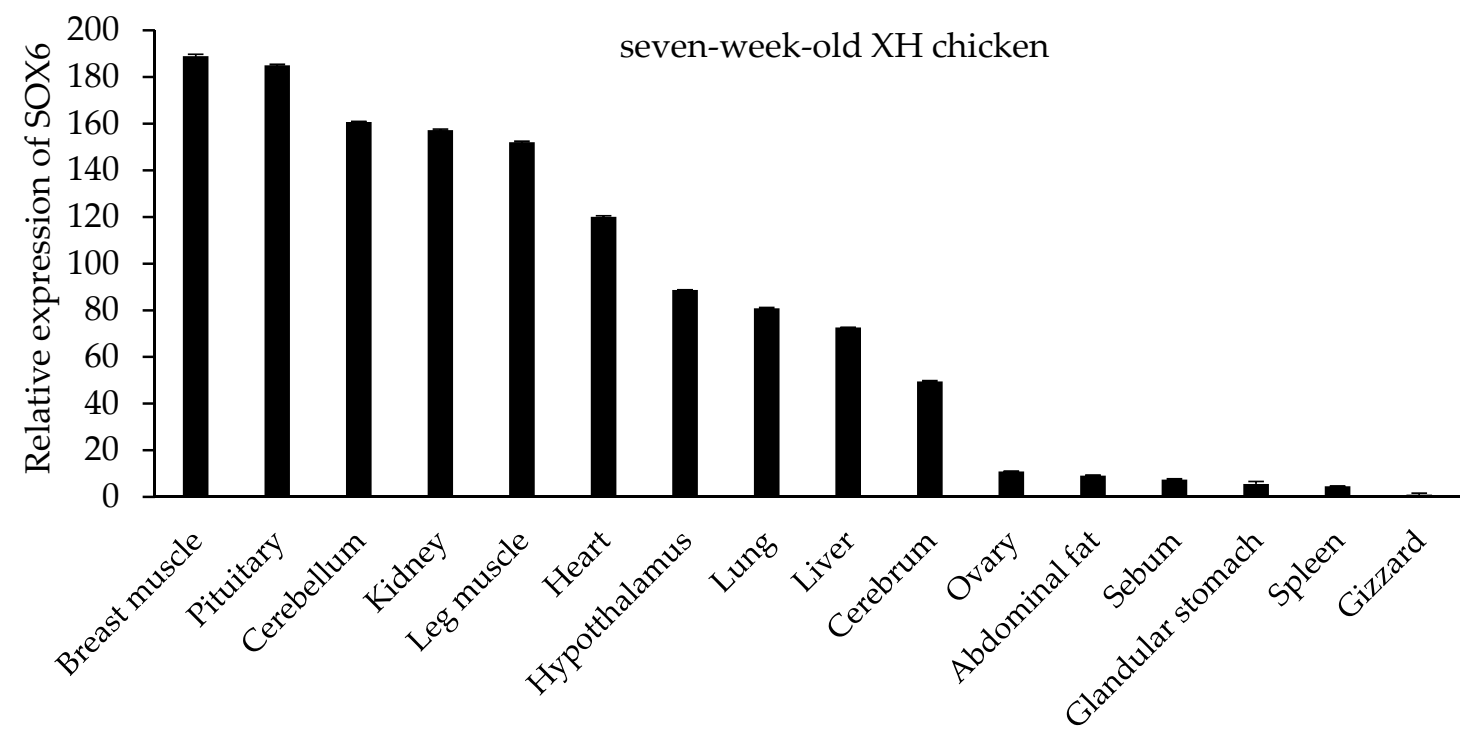

Figure 4. The tissue expression profile of SOX6 in seven-week-old XH chickens. 


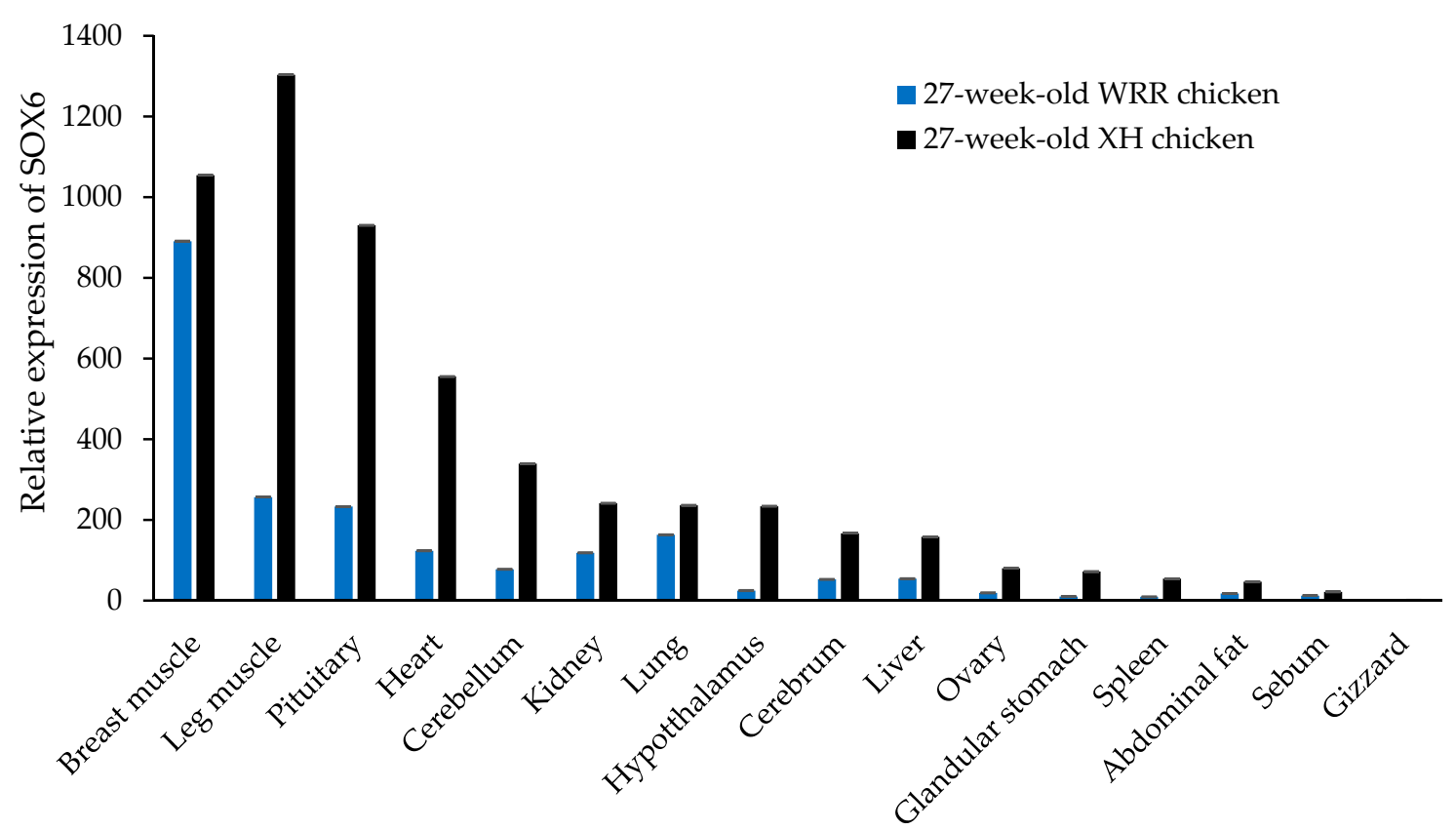

Figure 5. The tissue expression pattern of SOX6 in both 27-week-old XH and WRR chickens.

Additionally, the expression level of SOX6 in the breast muscle of variant $\mathrm{XH}$ chickens with $\mathrm{CN}=3$ was about two times higher than that of the normal individuals $(\mathrm{CN}=2)$, and that in the leg muscle, kidney and heart of the variant individuals was likewise higher than those of normal individuals (Figure 6a). The expression level of SOX6 in the pectoral muscle, leg muscle, kidney and heart of the WRR chickens was increased gradually along with an increase of the copy number (Figure 6b), though differences were not statistically significant. As shown in Table 7, there was a remarkably significant association between SOX6 expression and copy number in breast muscle both in $\mathrm{XH}$ and WRR chickens $(p<0.01)$.

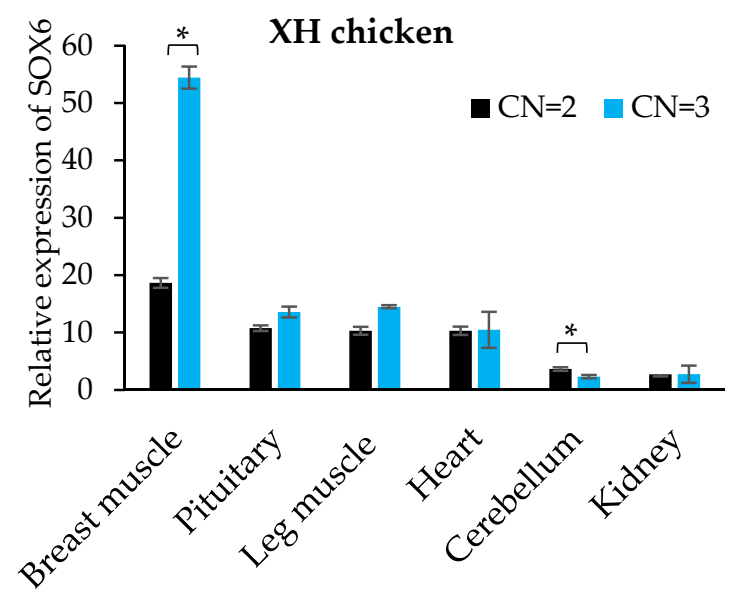

(a)

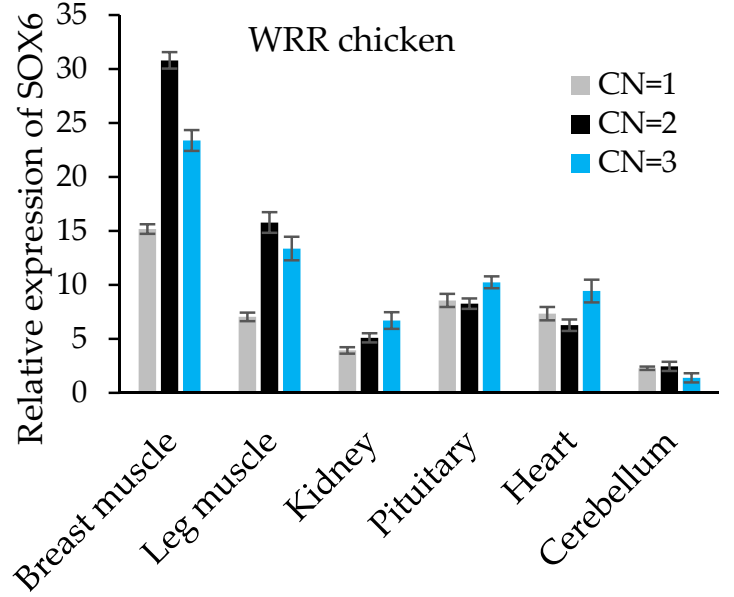

(b)

Figure 6. The expression levels of SOX6 in XH and WRR chickens with different copy numbers. $(\mathbf{a}, \mathbf{b})$ The relative expression levels of SOX6 in six tissues of both $\mathrm{XH}$ chicken with $\mathrm{CN}=2$ or 3 and WRR chicken with $C N=1,2$ or 3, respectively. The Significance: * indicates $p<0.05$. 
Table 7. The significance of association between SOX6 RNA expression and copy number ( $p$-value).

\begin{tabular}{ccccccc}
\hline & Breast Muscle & Pituitary & Leg Muscle & Heart & Cerebellum & Kidney \\
\hline XH & 0.0000323436 & 0.53629558 & 0.830763012 & 0.958416629 & 0.026859996 & 0.177897854 \\
WRR & 0.001143708 & 0.147867296 & 0.190177707 & 0.400274735 & 0.175778229 & 0.255664008 \\
\hline
\end{tabular}

\subsection{Disorder Region of SOX6 Proteins}

We used the Swiss model to predict the tertiary structure of SOX6 proteins by homologous construction. The results showed that the 132-264 aa and 580-649 aa regions of the SOX6 proteins had tertiary structures. Its tertiary structure prediction was similar to the secondary structure (Figure 7a,b). However, the proteins' tertiary structure was unable to be predicted in the 265-579 aa region. From the GlobPlot analysis of the SOX6 amino acid sequence, we found that the 307-508 aa was located in the disordered region and consistent with the prediction results of the Swiss model (Figure 7c).

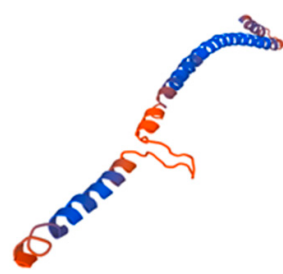

(a)

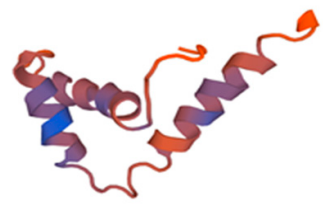

(b)

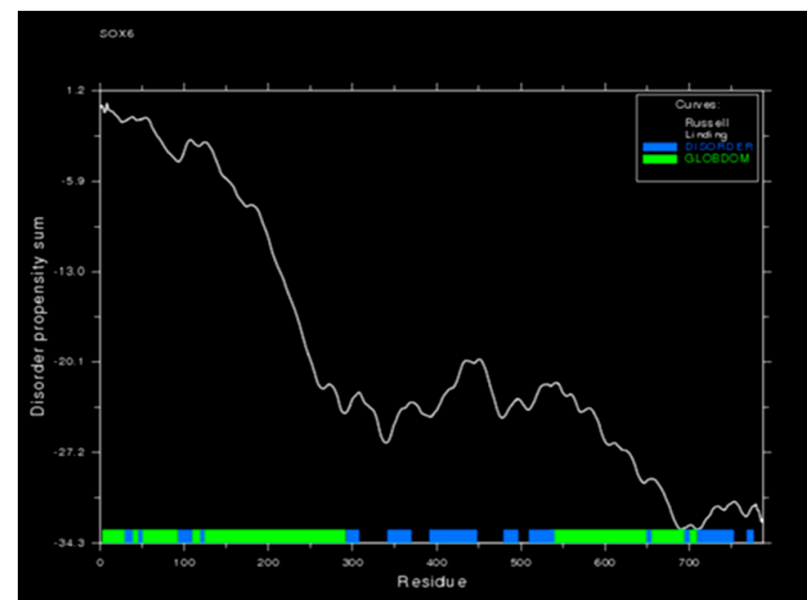

(c)

Figure 7. The disorder region of the SOX6 proteins is $265-579$ aa. $(\mathbf{a}, \mathbf{b})$ The prediction results of the tertiary structure of SOX6 proteins in 132-264 aa and 580-649 aa were shown on the left and right sides, respectively. (c) Prediction of the protein disorder region of the SOX6 proteins. The blue color represents a disordered protein, and green indicates that the protein has a fixed structure.

\subsection{Chicken SOX6 Promotes Skeletal Cell Proliferation and Differentiation}

The homology of SOX6 between quails and chickens is up to 99\% (Supplementary Table S1 and Figure S4), therefore, we used QM7 cells to serve as research material. As shown in Figure 8a, cells during the G1 phase were significantly decreased $(p<0.01)$, and while cells in the S phase were remarkably increased $(p<0.01)$ by overexpressing SOX6. We obtained the opposite result from the interference experiment (Figure $8 b$ ). In the cells of the general medium (GM), the differentiation medium from one day to five days (DM1-5), the expression level of SOX6 gradually increased (Figure 8c). It demonstrated that chicken SOX6 plays a positive role in muscle cell differentiation. 


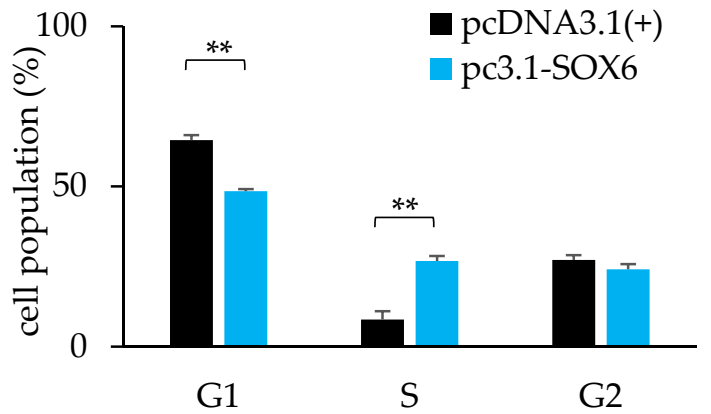

(a)

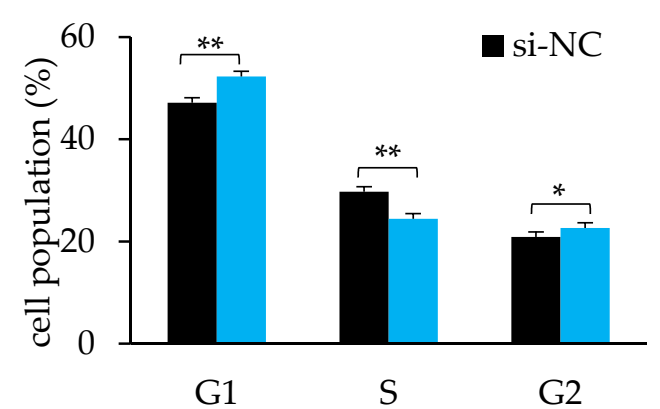

(b)

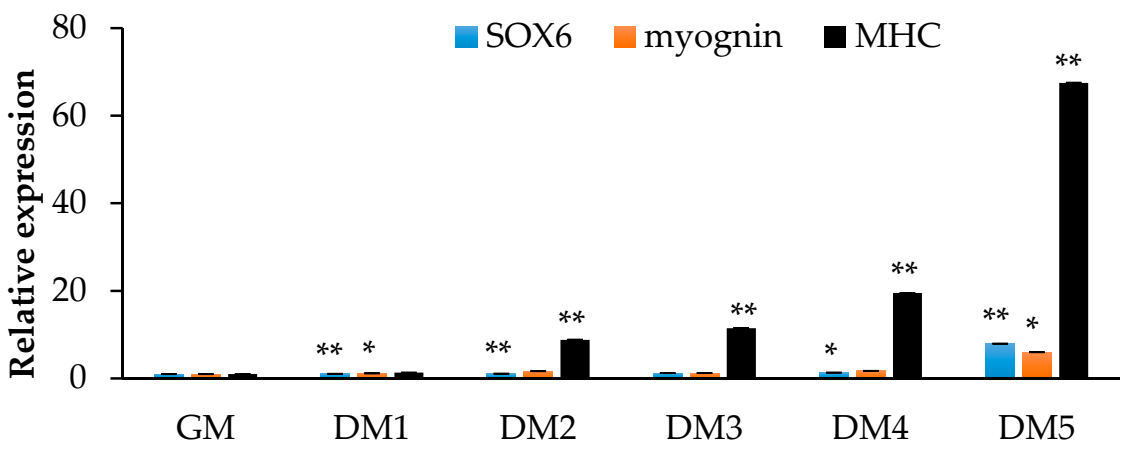

(c)

Figure 8. Chicken SOX6 promotes cell proliferation and differentiation. $(\mathbf{a}, \mathbf{b})$ The cell population of cell cycles after overexpressing or interference with SOX6, respectively. (c) The expression levels of SOX6, myognin and MHC in QM7 during differentiation medium from one to five days (DM1-5). Significance: ${ }^{*}{ }^{* *}$ indicate $p<0.05$ and $p<0.01$ vs. general medium (GM), respectively.

As shown in Figure 9, after the interference of the SOX6, the expression levels of those genes associated with growth and development, such as SHOX, MYF6, and IGFIR were significantly reduced $(p<0.05)$, and the expression levels of those genes associated with cell proliferation, for instance, SOX9 and CCND1 were also significantly reduced $(p<0.05)$.

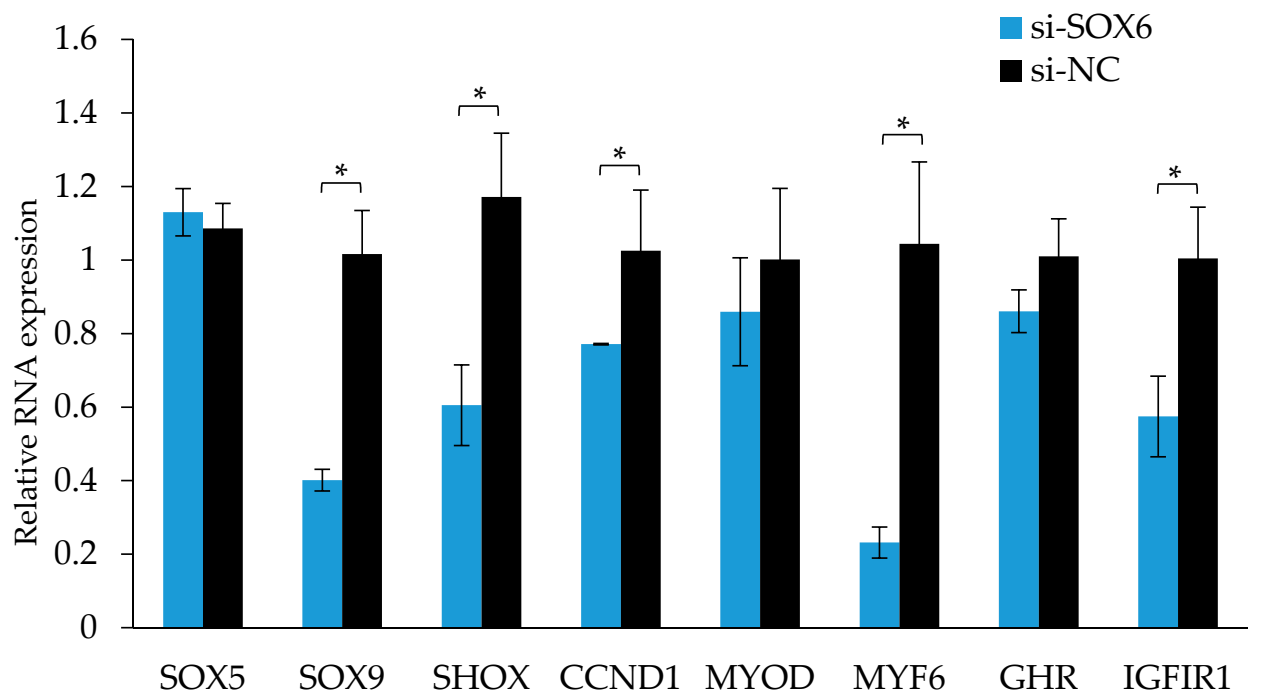

Figure 9. The RNA expression levels of candidate genes after interfering with SOX6 in the QM7 cells. Significance: * indicates $p<0.05$. 


\section{Discussion}

In order to better reveal the molecular mechanisms of phenotypic genetic variation, an association analysis between a large number of SNPs, genes' CNVRs and phenotypic traits was carried out [24]. The results show 10 CNPs containing many important chicken-growth-relevant genes, such as GLCCI1 [25,26], growth hormone receptor gene (CNP19) and SOX6 (CNP13). CNP13 overlaps with SOX6, which cooperated with SOX5 and SOX9 to participate in the development of a variety of organs and tissues $[27,28]$. We found that the copy number of the CNP13 could increase the expression level of SOX6, suggesting that CNP13 could regulate chicken growth through affecting the function of SOX6.

McCarroll et al. found that $99 \%$ of CNV variations are hereditary [2]. The results of CNV genetic law in this study also showed that most of the CNVs followed Mendel's principles, which were consistent with the genetic characteristics of $\mathrm{CNV}$, though some rare mutations were not consistent with Mendel's principles. We found that mutations appeared in CNP13 with a gradually decreased frequency of regional deletion in the resource group, and low frequency in other groups. However, the homozygous deletion $(0 / 0)$ individuals do not appear in the offspring. Since the deletion region probably plays an important function, pure deletion of individuals easily leads to serious abnormalities or disease, likely causing embryonal death, and was eliminated in the process of evolution [29]. An individual with $\mathrm{CN}=3(1 / 2)$ was found in this group by $\mathrm{CNVplex}{ }^{\circledR}$, which might be generated from the lack of individual variation (0/1) and normal individuals (1/1). Additionally, the repeated events in CNP10 and CNP13 were undertaken by positive selection pressure in evolution, which can be stably transmitted to the offspring. Those with genetic benefits on CNVs may have an important effect on some specific traits, pedigree evolution and formation. Therefore, it is necessary to further study CNVs to find out the candidate CNVs with important functions.

After SOX6 overexpression, a vector was transfected into muscle cells, and the cells in the S phase increased significantly. SOX6 may promote cell growth through promoting cells to transit from the G1 phase to the S phase. To understand the function of SOX6 in cell growth, we detect the expression of key cell-cycle regulatory factors after interfering with SOX6. For instance, CCND1 can promote cell proliferation, leading to transition tumor progression [30,31]. Insulin-like growth factor 1 (IGF-1) can play an important role in chicken growth through promoting DNA synthesis in the cell cycle to promoting cell proliferation [32]. IGF1R involves in the regulation of cell cycles, proliferation, differentiation, and metabolism, and its gene polymorphism is related to chicken growth and carcass traits $[33,34]$. Myogenic regulatory factors (MRFs) can regulate cell proliferation and differentiation. Myogenic differentiation antigens $(M Y O D)$ can promote myoblast differentiation, and have important effects on muscle development [35,36]. Myogenic factor 6 (MYF6) enhances the expression of muscle proteins and other related muscle-specific genes through trans-activation [37]. The expression level of CCND1, a cell-proliferation-promoting gene, was significantly decreased after the interference of SOX6 $(p<0.01)$. With the knockdown of SOX6, the expression levels of IGF1R and MYF6 was likewise decreased significantly. Chicken MYF6 is closely related to chicken meat quality and carcass traits [38], and CNP13 is related to leg muscle shear force and dry matter content, the MYF6 may combine with SOX6 (CNP13) and participate in chicken muscle growth and meat quality traits. The results showed that the expression levels of SOX9 and SHOX were significantly reduced after the interference of SOX6, suggesting that together these three genes play a similar role in chicken growth.

Tissue-specific gene expression is closely related to its biological function. Human SOX6 is highly expressed in nerve tissue [39]. However, high expression levels of SOX6 were found in chicken breast muscle, leg muscle, kidney, heart, cerebellum and pituitary. Since muscles and kidneys are closely related to the growth and development of individuals, the high expression of SOX6 in muscles suggests that it might have an effect on muscle growth and development.

As an important genetic variation, the dose effect of the copy number of a CNV can change gene structure, expression and even affect gene function. Previous results have showed that the gene copy number can cause a change in the expression level of mRNA. Some gene number variations are proportional to gene expression [40], and some are opposite [41]. We found that the mRNA expression 
of SOX6 in chicken breast muscle with an SOX6 repeat copy number is two times higher than that in normal individuals. In the muscle and kidney tissues of WRR chickens, the mRNA expression of SOX6 is proportional to the copy number of the gene. It is suggested that there might be an enhancer in the region to promote the expression level of SOX6. The number of enhancers is increased followed by an increase in the copy number in CNP13. Thereby, SOX6 is positively associated with the development of chicken muscle.

It was showed that GlobPlot online software could analyze the ordered or disordered regions of a protein [20]. In this study, from the GlobPlot analysis of the SOX6 amino acid sequence, we found that the 300-580 aa region is a disorder region. Notably, combined with the results of the CNVplex ${ }^{\circledR}$ analysis, a 378-508 peptide segment of SOX6 is located in the disordered region, which indicated that the CNV may be related to the disorder region of the SOX6 proteins. A major determinant of polypeptide segments folding co-operatively into a defined tertiary structure is the long-range hydrophobic interaction between amino acids in the linear sequence. Intrinsically disordered regions (IDRs) are polypeptide segments that do not contain sufficient hydrophobic amino acids to mediate co-operative folding. Instead, they typically contain a higher proportion of polar or charged amino acids [42]. Thus, IDRs lack a unique three-dimensional structure either entirely or in part in their native state. They generally shape a variety of conformations that are in dynamic equilibrium under physiological conditions [43,44]. These properties of IDRs make them well-suited to perform signaling and regulatory functions. Indeed, the functions of proteins with IDRs have revealed that they are enriched in signaling proteins and nucleic acid-binding proteins such as kinases, transcription factors and splicing factors [45-47]. In chicken, we found that the CNV of SOX6 genes resulted in a disorder structure of SOX6 proteins, which may interact with SOX9 and SHOX to repress the G1 phase and up-regulate the $S$ phase in the cell-cycle process, resulting in promotion of cell proliferation and differentiation. However, the limitations of this work were that we cannot clear out what kind of structures SOX6 genes have with or without CNVs in chicken, and what the different functions are between ordered and disordered SOX6 proteins.

\section{Conclusions}

We found that the expression level of SOX6 was positively increased by the copy number, and the disorder structure of SOX6 proteins could contribute to the development of muscle growth through up-regulating the expression levels of the muscle growth related genes in chickens as in other animal species.

Supplementary Materials: The following are available online at www.mdpi.com/2073-4425/9/1/42/s1. File1: Table S1: Homologous alignment of SOX6 coding sequences among 12 different species (\%). Table S2: Primers used in analysis of CNP analysis in chicken. TableS S3-S11: Population genetic of CNV in family 1, 5, 7, 8, 10, 13, 15, 16 and 17, respectively. Figure S2: LD analysis between six candidate CNPs and their SNPs in $500 \mathrm{~kb}$ on either side. Figure S3: The result of CNVplex ${ }^{\circledR}$ assay using different probes in three CNPs. Figure S4: Phylogenetic tree of SOX6 proteins among different species. File2: The result of CNVplex ${ }^{\circledR}$ assay.

Acknowledgments: We would like to thank Shanghai Genesky Biotechnologies Inc. (Shanghai, China) for analyzing the copy number detection. This work was funded by the High Technology Research and Development Program of China (2013AA102501), and the China Agriculture Research System (CARS-41-G03).

Author Contributions: S.L. and X.L. conceived, designed and performed the experiments. X.L. analyzed the data. S.L. wrote the paper. Z.Z. and M.J. were involved in the cell culture and transient transfected experiments. Y.R. and Q.N. provided many precious opinions on statistical analyses and revising this manuscript. X.Z. participated in conceiving the study, the experimental design and data analysis and finalized the manuscript. All authors have read and approved the final manuscript.

Conflicts of Interest: The authors declare no conflict of interest. 


\section{References}

1. Redon, R.; Ishikawa, S.; Fitch, K.R.; Feuk, L.; Perry, G.H.; Andrews, T.D.; Fiegler, H.; Shapero, M.H.; Carson, A.R.; Chen, W.; et al. Global variation in copy number in the human genome. Nature 2006, 444, 444-454. [CrossRef] [PubMed]

2. McCarroll, S.A.; Altshuler, D.M. Copy-number variation and association studies of human disease. Nat. Genet. 2007, 39, S37-S42. [CrossRef] [PubMed]

3. Zhang, F.; Gu, W.; Hurles, M.E.; Lupski, J.R. Copy number variation in human health, disease, and evolution. Annu. Rev. Genom. Hum. Genet. 2009, 10, 451-481. [CrossRef] [PubMed]

4. $\quad$ Elferink, M.G.; Vallee, A.A.; Jungerius, A.P.; Crooijmans, R.P.; Groenen, M.A. Partial duplication of the PRLR and SPEF2 genes at the late feathering locus in chicken. BMC Genom. 2008, 9, 391. [CrossRef] [PubMed]

5. Wright, D.; Boije, H.; Meadows, J.R.; Bed'Hom, B.; Gourichon, D.; Vieaud, A.; Tixier-Boichard, M.; Rubin, C.J.; Imsland, F.; Hallbook, F.; et al. Copy number variation in intron 1 of SOX 5 causes the Pea-comb phenotype in chickens. PLoS Genet. 2009, 5, e1000512. [CrossRef] [PubMed]

6. Dorshorst, B.; Molin, A.M.; Rubin, C.J.; Johansson, A.M.; Stromstedt, L.; Pham, M.H.; Chen, C.F.; Hallbook, F.; Ashwell, C.; Andersson, L. A complex genomic rearrangement involving the endothelin 3 locus causes dermal hyperpigmentation in the chicken. PLoS Genet. 2011, 7, e1002412. [CrossRef] [PubMed]

7. Luo, J.; Yu, Y.; Mitra, A.; Chang, S.; Zhang, H.; Liu, G.; Yang, N.; Song, J. Genome-wide copy number variant analysis in inbred chickens lines with different susceptibility to Marek's disease. G3 (Bethesda) 2013, 3, 217-223. [CrossRef] [PubMed]

8. Pevny, L.H.; Lovell-Badge, R. Sox genes find their feet. Curr. Opin. Genet. Dev. 1997, 7, 338-344. [CrossRef]

9. Mackie, E.J.; Ahmed, Y.A.; Tatarczuch, L.; Chen, K.S.; Mirams, M. Endochondral ossification: How cartilage is converted into bone in the developing skeleton. Int. J. Biochem. Cell Biol. 2008, 40, 46-62. [CrossRef] [PubMed]

10. Kim, H.J.; Im, G.I. Electroporation-mediated transfer of SOX trio genes (SOX-5, SOX-6, and SOX-9) to enhance the chondrogenesis of mesenchymal stem cells. Stem Cells Dev. 2011, 20, 2103-2114. [CrossRef] [PubMed]

11. Aza-Carmona, M.; Shears, D.J.; Yuste-Checa, P.; Barca-Tierno, V.; Hisado-Oliva, A.; Belinchon, A.; Benito-Sanz, S.; Rodriguez, J.I.; Argente, J.; Campos-Barros, A.; et al. SHOX interacts with the chondrogenic transcription factors SOX5 and SOX6 to activate the aggrecan enhancer. Hum. Mol. Genet. 2011, 20, 1547-1559. [CrossRef] [PubMed]

12. Jackson, H.E.; Ono, Y.; Wang, X.; Elworthy, S.; Cunliffe, V.T.; Ingham, P.W. The role of Sox6 in zebrafish muscle fiber type specification. Skelet. Muscle 2015, 5. [CrossRef] [PubMed]

13. Hagiwara, N.; Yeh, M.; Liu, A. Sox6 is required for normal fiber type differentiation of fetal skeletal muscle in mice. Dev. Dyn. 2007, 236, 2062-2076. [CrossRef] [PubMed]

14. An, C.I.; Dong, Y.; Hagiwara, N. Genome-wide mapping of Sox6 binding sites in skeletal muscle reveals both direct and indirect regulation of muscle terminal differentiation by Sox6. BMC Dev. Biol. 2011, 11, 59. [CrossRef] [PubMed]

15. Rao, Y.S.; Li, J.; Zhang, R.; Lin, X.R.; Xu, J.G.; Xie, L.; Xu, Z.Q.; Wang, L.; Gan, J.K.; Xie, X.J.; et al. Copy number variation identification and analysis of the chicken genome using a 60K SNP BeadChip. Poult. Sci. 2016, 95, 1750-1756. [CrossRef] [PubMed]

16. Xie, L.; Luo, C.; Zhang, C.; Zhang, R.; Tang, J.; Nie, Q.; Ma, L.; Hu, X.; Li, N.; Da, Y.; et al. Genome-wide association study identified a narrow chromosome 1 region associated with chicken growth traits. PLoS ONE 2012, 7, e30910. [CrossRef] [PubMed]

17. Xu, Z.; Ji, C.; Zhang, Y.; Zhang, Z.; Nie, Q.; Xu, J.; Zhang, D.; Zhang, X. Combination analysis of genome-wide association and transcriptome sequencing of residual feed intake in quality chickens. BMC Genom. 2016, 17, 594. [CrossRef] [PubMed]

18. Tamura, K.; Stecher, G.; Peterson, D.; Filipski, A.; Kumar, S. MEGA6: Molecular Evolutionary Genetics Analysis version 6.0. Mol Biol Evol. 2013, 30, W2725-W2729. [CrossRef] [PubMed]

19. Biasini, M.; Bienert, S.; Waterhouse, A.; Arnold, K.; Studer, G.; Schmidt, T.; Kiefer, F.; Gallo Cassarino, T.; Bertoni, M.; Bordoli, L.; et al. SWISS-MODEL: modelling protein tertiary and quaternary structure using evolutionary information. Nucleic Acids Res. 2014, 42, W252-W258. [CrossRef] [PubMed] 
20. Majczak, G.; Lilla, S.; Garay-Malpartida, M.; Markovic, J.; Medrano, F.J.; de Nucci, G.; Belizário, J.E. Prediction and biochemical characterization of intrinsic disorder in the structure of proteolysis-inducing factor/dermcidin. Genet. Mol. Res. 2007, 6, 1000-1011. [PubMed]

21. Du, R.; Lu, C.; Jiang, Z.; Li, S.; Ma, R.; An, H.; Xu, M.; An, Y.; Xia, Y.; Jin, L.; et al. Efficient typing of copy number variations in a segmental duplication-mediated rearrangement hotspot using multiplex competitive amplification. J. Hum. Genet. 2012, 57, 545-551. [CrossRef] [PubMed]

22. Zhang, X.; Xu, Y.; Liu, D.; Geng, J.; Chen, S.; Jiang, Z.; Fu, Q.; Sun, K. A modified multiplex ligation-dependent probe amplification method for the detection of 22q11.2 copy number variations in patients with congenital heart disease. BMC Genom. 2015, 16, 364. [CrossRef] [PubMed]

23. Derveaux, S.; Vandesompele, J.; Hellemans, J. How to do successful gene expression analysis using real-time PCR. Methods 2010, 50, 227-230. [CrossRef] [PubMed]

24. Beckmann, J.S.; Estivill, X.; Antonarakis, S.E. Copy number variants and genetic traits: Closer to the resolution of phenotypic to genotypic variability. Nat. Rev. Genet. 2007, 8, 639-646. [CrossRef] [PubMed]

25. Crooijmans, R.P.; Fife, M.S.; Fitzgerald, T.W.; Strickland, S.; Cheng, H.H.; Kaiser, P.; Redon, R.; Groenen, M.A. Large scale variation in DNA copy number in chicken breeds. BMC Genom. 2013, 14, 398. [CrossRef] [PubMed]

26. Cheong, H.I.; Kang, H.G.; Schlondorff, J. GLCCI1 single nucleotide polymorphisms in pediatric nephrotic syndrome. Pediatr. Nephrol. 2012, 27, 1595-1599. [CrossRef] [PubMed]

27. Liu, C.F.; Lefebvre, V. The transcription factors SOX9 and SOX5/SOX6 cooperate genome-wide through super-enhancers to drive chondrogenesis. Nucleic Acids Res. 2015, 43, 8183-8203. [CrossRef] [PubMed]

28. Baroti, T.; Zimmermann, Y.; Schillinger, A.; Liu, L.; Lommes, P.; Wegner, M.; Stolt, C.C. Transcription factors Sox 5 and Sox6 exert direct and indirect influences on oligodendroglial migration in spinal cord and forebrain. Glia 2016, 64, 122-138. [CrossRef] [PubMed]

29. Freeman, J.L.; Perry, G.H.; Feuk, L.; Redon, R.; McCarroll, S.A.; Altshuler, D.M.; Aburatani, H.; Jones, K.W.; Tyler-Smith, C.; Hurles, M.E.; et al. Copy number variation: New insights in genome diversity. Genome Res. 2006, 16, 949-961. [CrossRef] [PubMed]

30. Hunter, T.; Pines, J. Cyclins and cancer. II: Cyclin D and CDK inhibitors come of age. Cell 1994, 79, 573-582. [CrossRef]

31. Sherr, C.J. The Pezcoller lecture: Cancer cell cycles revisited. Cancer Res. 2000, 60, 3689-3695. [PubMed]

32. Liu, B.; Yang, L.; Huang, B.; Cheng, M.; Wang, H.; Li, Y.; Huang, D.; Zheng, J.; Li, Q.; Zhang, X.; et al. A functional copy-number variation in MAPKAPK2 predicts risk and prognosis of lung cancer. Am. J. Hum. Genet. 2012, 91, 384-390. [CrossRef] [PubMed]

33. Lei, M.; Peng, X.; Zhou, M.; Luo, C.; Nie, Q.; Zhang, X. Polymorphisms of the IGF1R gene and their genetic effects on chicken early growth and carcass traits. BMC Genet. 2008, 9, 70. [CrossRef] [PubMed]

34. Tosca, L.; Chabrolle, C.; Crochet, S.; Tesseraud, S.; Dupont, J. IGF-1 receptor signaling pathways and effects of AMPK activation on IGF-1-induced progesterone secretion in hen granulosa cells. Domest. Anim. Endocrinol. 2008, 34, 204-216. [CrossRef] [PubMed]

35. Ling, B.M.; Bharathy, N.; Chung, T.K.; Kok, W.K.; Li, S.; Tan, Y.H.; Rao, V.K.; Gopinadhan, S.; Sartorelli, V.; Walsh, M.J.; et al. Lysine methyltransferase G9a methylates the transcription factor MyoD and regulates skeletal muscle differentiation. Proc. Natl. Acad. Sci. USA 2012, 109, 841-846. [CrossRef] [PubMed]

36. Zhang, X.; Patel, S.P.; McCarthy, J.J.; Rabchevsky, A.G.; Goldhamer, D.J.; Esser, K.A. A non-canonical E-box within the MyoD core enhancer is necessary for circadian expression in skeletal muscle. Nucleic Acids Res. 2012, 40, 3419-3430. [CrossRef] [PubMed]

37. Fan, H.; Cinar, M.U.; Phatsara, C.; Tesfaye, D.; Tholen, E.; Looft, C.; Schellander, K. Molecular mechanism underlying the differential MYF6 expression in postnatal skeletal muscle of Duroc and Pietrain breeds. Gene 2011, 486, 8-14. [CrossRef] [PubMed]

38. Te Pas, M.F.; Verburg, F.J.; Gerritsen, C.L.; de Greef, K.H. Messenger ribonucleic acid expression of the MyoD gene family in muscle tissue at slaughter in relation to selection for porcine growth rate. J. Anim. Sci. 2000, 78, 69-77. [CrossRef] [PubMed]

39. Rudrabhatla, P.; Utreras, E.; Jaffe, H.; Kulkarni, A.B. Regulation of Sox 6 by cyclin dependent kinase 5 in brain. PLoS ONE 2014, 9, e89310. [CrossRef] [PubMed] 
40. Wong, K.K.; deLeeuw, R.J.; Dosanjh, N.S.; Kimm, L.R.; Cheng, Z.; Horsman, D.E.; MacAulay, C.; Ng, R.T.; Brown, C.J.; Eichler, E.E.; et al. A comprehensive analysis of common copy-number variations in the human genome. Am. J. Hum. Genet. 2007, 80, 91-104. [CrossRef] [PubMed]

41. Xu, Y.; Shi, T.; Cai, H.; Zhou, Y.; Lan, X.; Zhang, C.; Lei, C.; Qi, X.; Chen, H. Associations of MYH3 gene copy number variations with transcriptional expression and growth traits in Chinese cattle. Gene 2014, 535, 106-111. [CrossRef] [PubMed]

42. Uversky, V.N.; Gillespie, J.R.; Fink, A.L. Why are "natively unfolded" proteins unstructured under physiologic conditions? Proteins 2000, 41, 415-427. [CrossRef]

43. Dyson, H.J.; Wright, P.E. Intrinsically unstructured proteins and their functions. Nat. Rev. Mol. Cell Biol. 2005, 6, 197-208. [CrossRef] [PubMed]

44. Forman-Kay, J.D.; Mittag, T. From sequence and forces to structure, function, and evolution of intrinsically disordered proteins. Structure 2013, 21, 1492-1499. [CrossRef] [PubMed]

45. Singh, G.P.; Dash, D. Intrinsic disorder in yeast transcriptional regulatory network. Proteins 2007, 68, 602-605. [CrossRef] [PubMed]

46. Patil, A.; Nakamura, H. Disordered domains and high surface charge confer hubs with the ability to interact with multiple proteins in interaction networks. FEBS Lett. 2006, 580, 2041-2045. [CrossRef] [PubMed]

47. Dunker, A.K.; Bondos, S.E.; Huang, F.; Oldfield, C.J. Intrinsically disordered proteins and multicellular organisms. Semin. Cell. Dev. Biol. 2015, 37, 44-55. [CrossRef] [PubMed]

(C) 2018 by the authors. Licensee MDPI, Basel, Switzerland. This article is an open access article distributed under the terms and conditions of the Creative Commons Attribution (CC BY) license (http://creativecommons.org/licenses/by/4.0/). 